\title{
Initial Volume of Distribution Normalized by Body Mass Index
}

National Cancer Institute

\section{Source}

National Cancer Institute. Initial Volume of Distribution Normalized by Body Mass Index. NCl Thesaurus. Code C102372.

The initial volume of distribution for a substance administered by bolus intravascular dosing divided by the body mass index. 